\title{
ESPAÑA: LA VIOLENCIA DOMÉSTICA Y EL DERECHO DE EXTRANJERÍA*
}

\begin{abstract}
Alfonso ORTEGA GIMÉNEZ**
RESUMEN: Hoy en día, la violencia doméstica se ha convertido en una lacra social, y en un problema social por el número de víctimas que produce. En este contexto, el hecho de que España se haya convertido, de un tiempo a esta parte, en país de acogida de inmigrantes - pues es "puerta de Europa"- ha traído, desgraciadamente, como consecuencia, que la persona extranjera se configure como una víctima más de la violencia doméstica. De esta forma, todos los poderes públicos están actuando, elaborando numerosos instrumentos jurídicos - bien articulados técnicamente-, que han nacido con el fin de atajar, desde el inicio, cualquier conducta que en el futuro pueda degenerar en hechos aún más graves.
\end{abstract}

ABSTRACT: Today, domestic violence has become a social evil, and in a social problem by the number of victims it produces. In this context, the fact that Spain has become, for some time now, in the host country of immigrants - because it is "door of Europe"- has resulted, unfortunately, as a result, the foreign person is set as a victim of domestic violence. Thus, all public authorities are acting, producing numerous legal instruments - technically well articulated-, who were born in order to tackle, from the outset, any conduct that in the future could degenerate into action even more serious.

RÉSUMÉ: Aujourd'hui, la violence domestique est devenu une scorie sociale et un problème social par le numéro de victimes que produit. Dans ce contexte, le fait que Espagne est devenu dernièrement un pays d'adoption d'immigrants car est "un porte d'Europe" a contribue malheureux ment a faire que la personne étranger se configure comme un victime de la violence domestique. De cet manière, tout le gouvernement agissent en l'élaboration de divers instruments juridiques qu'ont née avec le fin du arrêter tout comportement que pourrait dégénérer dans le future en événements plus graves.

* Artículo recibido el 8 de julio de 2008 y aceptado para su publicación el 15 de agosto de 2008.

** Profesor de Derecho internacional privado en la Universidad "Miguel Hernández" de Elche, España. 
Las mujeres pueden romper el círculo de los malos tratos y gritar al aire que son libres.

Alicia HERRERA

SUMARIO: I. Planteamiento. II. La violencia doméstica y el derecho de extranjería español. III. Conclusiones. IV. Bibliografia.

\section{PLANTEAMIENTO}

1. De todos es sabido que, desgraciadamente, en la actualidad, la violencia doméstica ${ }^{1}$ — como una forma más de violencia "perpetrada en el ám-

1 La violencia en el ámbito familiar ("violencia doméstica") comprende: a) la violencia física, considerando ésta como cualquier acción no accidental que provoque o pueda provocar daño físico, enfermedad o riesgo de padecerla; b) la violencia psíquica, considerando como tal los actos, conductas o exposición a situaciones que agredan o puedan agredir, alteren o puedan alterar el contexto afectivo necesario para el desarrollo psicológico normal, tales como rechazos, insultos, amenazas, humillaciones, aislamiento; c) la violencia sexual, como toda actividad dirigida a la ejecución de actos sexuales en contra de la voluntad, dolorosos o humillantes o abusando del poder, autoridad, con engaño o por desconocimiento, en el caso de los menores; d) la violencia económica, como la desigualdad en el acceso a los recursos económicos que deben ser compartidos, al derecho de propiedad, a la educación y a un puesto de trabajo, derechos reconocidos en la Constitución española; e) la corrupción, como conductas desviadas, antisociales o desadaptadas que impiden la integración social (inducción a la delincuencia, explotación sexual, etcétera), y f) la explotación laboral y mendicidad, son situaciones en las que mediante abuso de poder o por fuerza y con violencia un miembro de la familia obliga a la práctica continuada de trabajos o actividades que o bien interfieren en el normal desarrollo o exceden de los límites de lo considerado normal en función de la edad, sexo, formación, o que se consideran humillantes o antisociales. Para más información, veánse, entre otros: Acale Sánchez, María, "La mujer como víctima de los malos tratos en el ámbito familiar", $M u$ jer, familia y derecho, Cádiz, Universidad de Cádiz, 2003, pp. 151-181; Alastuey Dobón, María Carmen, "Desarrollo parlamentario de la ley integral contra la violencia de género: consideraciones críticas", La reforma penal en torno a la violencia doméstica y de género, Barcelona, Atelier, 2006, pp. 57-68; Andrés Domingo, Paloma, "Violencia contra las mujeres, violencia de género", La violencia contra las mujeres: prevención y detección: cómo promover desde los servicios sanitarios relaciones autónomas, solidarias y gozosas, Madrid, Díaz de Santos, 2004, pp. 17-38; Aranguez Sánchez, Carlos, "El delito de maltrato doméstico y de género del artículo 153 CP", Estudios penales en homenaje al profesor Cobo del Rosal, Madrid, Dykinson, 2005, pp. 11-33; Armero Villalba, Silvia, "Tratamiento legal en España del maltrato familiar", Estudios sobre la violencia familiar 
bito familiar, es decir, en el ámbito privado" $2^{2}$ se ha convertido en una lacra social, en una nueva forma, como han señalado algunos autores - aunque, eso sí, circunscrita a la violencia de género- de "terrorismo doméstico", 3 aunque se han convertido en habituales las noticias referidas a sucesos de este tipo, no podemos acostumbrarnos a semejantes actos.

La violencia doméstica se configura, en nuestros días, como un problema social por el número de víctimas que produce - así, en España, según datos del Instituto de la Mujer, sufren maltrato 2.5 millones de mujeres españolas - ${ }^{4}$ que exige respuestas que nazcan desde la sociedad, esto es, no sólo desde la administración, sino también desde los administrados, sin cuya ayuda cualquier medida sería "inútil".

2. En este contexto, la violencia de género ${ }^{5}$ - manifestación, junto con la violencia contra la infancia, contra los ancianos y de los jóvenes

y agresiones sexuales, Madrid, Centro de Estudios Jurídicos de la Administración de Justicia, 2001, pp. 11-52; Benítez Jiménez, María José, Violencia contra la mujer en el ámbito familiar: cambios sociales y legislativos, Madrid, Edisofer, 2004; Campos Cristóbal, Raquel, "Tratamiento penal de la violencia de género", La nueva ley contra la violencia de género: LO 1/2004, de 28 de diciembre. Madrid, Madrid, Iustel, 2005, pp. 251-274; Chato Franco, Mercedes et al., Guía de los derechos de las mujeres víctimas de violencia familiar, Madrid, Asociación de Mujeres Juristas-Themis, 2001; Magro Servet, Vicente, Soluciones de la sociedad española ante la violencia que se ejerce sobre las mujeres, Madrid, La Ley, 2005; Marín de Espinosa Ceballos, Elena B., La violencia doméstica: análisis sociológico, dogmático y de derecho comparado, Granada, Comares, 2001; Mayordomo Rodrigo, Virginia, La violencia contra la mujer: un estudio de derecho comparado, Madrid, Dilex, 2005; Tirado Estrada, Jesús J., "Maltrato familiar: perspectivas latinoamericanas", Estudios sobre la violencia familiar y agresiones sexuales, Madrid, Centro de Estudios Jurídicos de la Administración de Justicia, 2001, pp.119-159.

2 Véase Marina Torres, José Antonio, "Violencia doméstica como problema social", Encuentros "Violencia doméstica", Madrid, Consejo General del Poder Judicial, Centro de Documentación Judicial, 2004, p. 631.

3 Véase en este sentido, Domínguez Martín, Almudena, "Violencia de género, terrorismo doméstico", Revista Lex Nova, Madrid, núm. 40, abril-junio de 2005, pp. 18-21.

4 Véase Marina Torres, José Antonio, op. cit., nota 2, pp. 637 y 638.

5 La expresión "violencia de género" es la traducción del inglés gender-based violence o gender violence, expresión difundida a raíz del Congreso sobre la Mujer celebrado en Pekín en 1995 bajo los auspicios de la ONU. En el inglés se documenta desde antiguo un uso traslaticio de gender como sinónimo de sex, sin duda nacido del empeño puritano en evitar este vocablo. Con el auge de los estudios feministas, en los años sesenta del siglo XX se comenzó a utilizar en el mundo anglosajón el término gender con el sentido de "sexo de un ser humano" desde el punto de vista específico de las diferencias sociales y culturales, en oposición a las biológicas, existentes entre hombres y mujeres. Sin embargo, en español las palabras tienen género (y no sexo), mientras que los seres vi- 
contra sus padres, de la violencia doméstica - constituye un ataque a los derechos humanos ${ }^{6}$ y un grave problema de nuestra sociedad. En total, en 2006 las mujeres presentaron 62,145 denuncias por malos tratos; de los cuales 18,745 son denuncias presentadas por extranjeras. ${ }^{7}$ De esta forma,

vos tienen sexo (y no género). En español no existe tradición de uso de la palabra "género" como sinónimo de sexo. Así pues, mientras que con la voz "sexo" se designa una categoría meramente orgánica, biológica, con el término "género" se ha venido aludiendo a una categoría sociocultural que implica diferencias o desigualdades de índole social, económica, política, laboral, etcétera. En esa línea se habla de estudios de género, discriminación de género, violencia de género, etcétera. Y sobre esa base se ha llegado a veces a extender el uso del término género hasta su equivalencia con sexo. Además, cabe resaltar que violencia de género también cabría considerarse como del género femenino al género masculino, algo que no se contempla en la ley, y no engloba la violencia entre homosexuales o contra otros miembros del ámbito familiar. Para más información, véase, entre otros: Díaz-Aguado Jalón, María José y Martínez Arias, Rosario, Estudio sobre las medidas adoptadas, por los Estados miembros de la Unión Europea, para luchar contra la violencia hacia las mujeres, Madrid, Instituto de la Mujer, 2002; Durán Febrer, María, "La ley contra la violencia de género en el contexto internacional", Temas para el debate, núm. 133 (2005), pp. 23-26; González Pillado, Esther y Fernández Fustes, Ma. Dolores, Violencia de género, Madrid, Boletín Oficial del Estado, 2006; Magariños Yánez, José Alberto, El derecho contra la violencia de género: análisis de la respuesta del ordenamiento jurídico internacional, comunitario, comparado, español y autonómico. Enfoque multidisciplinar del problema, Madrid, Montecorvo, 2007; Mallaina García, Carmela, "Los derechos de las mujeres víctimas de violencia", Estudios sobre la ley integral contra la violencia de género, Madrid, Dykinson, 2005, pp. 61-87; Montalbán Huertas, Inmaculada, Perspectiva de género: criterio de interpretación internacional y constitucional, Madrid, Consejo General del Poder Judicial, 2004.

6 El Comité para la Eliminación de la Discriminación contra la Mujer, en la Recomendación General 19, 1992, documento ONU A/47/38, define la discriminación contra la mujer de forma que dicha definición incluye la violencia basada en el sexo, es decir, la violencia dirigida contra la mujer porque es mujer o que la afecta en forma desproporcionada. Incluye actos que infligen daños o sufrimientos de índole física, mental o sexual, amenazas de cometer esos actos, coacción y otras formas de privación de la libertad. La violencia contra la mujer puede contravenir disposiciones de la Convención, sin tener en cuenta si hablan expresamente de la violencia.

7 Las mujeres extranjeras víctimas de la violencia de género denuncian más que las españolas; así lo revelan los últimos datos del Ministerio del Interior, que dejan ver que las denuncias presentadas por este colectivo ha crecido un $30 \%$ en los últimos tres años, frente al incremento del $0.5 \%$ en el mismo periodo de tiempo de las presentadas por las españolas. Además, de las 18,740 denuncias presentadas por ciudadanas extranjeras en 2006, casi la mitad de ellas $(9,138)$ fueron de mujeres ecuatorianas, colombianas, rumanas y marroquíes. Por otro lado, en 2006, es de destacar que fueron presentadas 24,326 denuncias contra los hombres de nacionalidad española, y contra los extranjeros fueron 7,639 , mientras que las presentadas contra las mujeres españolas fueron 6,192 , y contra 
el hecho de que España se haya convertido, de un tiempo a esta parte, en país de acogida de inmigrantes ${ }^{8}$ — pues es "puerta de Europa"- ha traído, desgraciadamente, como consecuencia, que la persona extranjera se configure como una víctima más de la violencia doméstica. ${ }^{9}$

3. De un tiempo a esta parte, todos los poderes públicos están actuando para acabar con esta lacra social, elaborando numerosos instrumentos jurídicos — bien articulados técnicamente-, que han nacido con el fin de atajar, desde el inicio, cualquier conducta que en el futuro pueda degenerar en hechos aún más graves. ${ }^{10}$

las extranjeras 1,316. En concreto, las ecuatorianas presentaron un total de 3,415 denuncias por malos tratos, las colombianas 1,951 , las rumanas 1,941 y las marroquíes 1,831 . En cuarto lugar se sitúan las ciudadanas de origen boliviano, con un total de 1,623. En lo que se refiere a las ciudadanas de países de la UE de los 25 - quedan excluidas Rumania y Bulgaria-, destacan las británicas, con un total de 781 denuncias presentadas a lo largo del año pasado. A más distancia se sitúan las alemanas (268), las francesas (215), o las italianas (104). La evolución de las denuncias presentadas por las ciudadanas de origen extranjero ha ido en aumento en los últimos tres años: 14,339 (2004), 16,464 (2005) y 18,745 (2006), con un incremento del 30 por ciento, frente a las denuncias de las españolas, que han pasado, en el mismo periodo de tiempo, de las 43,186 a las 43,400, lo que supone un incremento de apenas un 0.5 por ciento. Por otra parte, en lo que va de 2007 , un total de 11 ciudadanas extranjeras han perdido la vida a manos de su pareja o ex pareja, frente a las 15 españolas. En concreto, el Instituto de la Mujer ha contabilizado la muerte de siete mujeres procedentes de Latinoamérica, que es el grupo más numeroso, una originaria de Marruecos, una de alguno de los países de la Unión Europea y 2 de países europeos no comunitarios. De esta manera, los datos del Instituto de la Mujer muestran que durante los últimos nueve años han fallecido 114 mujeres extranjeras frente a las 380 españolas. En lo que se refiere a los agresores, ocho de los 18 responsables de la muerte de su pareja o ex pareja son de nacionalidad extranjera: un rumano, dos africanos y tres latinoamericanos. La evolución de agresores extranjeros ha sido la siguiente: 4 (1999), 8 (2000), 13 (2001), 12 (2002), 11 (2003), 18 (2004), 15 (2005) y 18 (2006).

8 Buena prueba de ello es que el $9 \%$ de todas las personas que viven en España —aproximadamente 4.000,000 de personas—, según el Instituto Nacional de Estadística, son extranjeros.

9 Si bien es cierto que no hay una relación causal entre la inmigración y la violencia, ya que las condiciones de la mujer en su país de origen pudieron convertirla también en víctima de la violencia doméstica, sirva como botón de muestra de lo apuntado el hecho de que en los últimos meses ha incrementado la presencia de extranjeros en los cursos de reeducación para maltratadores; por ejemplo, en los cursos seguidos en la Audiencia Provincial de Alicante (España), la asistencia de extranjeros es del 20\% frente al $80 \%$ de nacionales.

10 Se debe advertir que el legislador español ha tenido que esperar hasta 2003 para regular, en general, la "violencia de género", y, en particular, los efectos de este desagra- 
El primero de esos instrumentos jurídicos a los que nos vamos a referir, en las líneas siguientes, fue la Ley 11/2003, del 29 de septiembre, de medidas concretas en materia de seguridad ciudadana, violencia doméstica e integración social de los extranjeros (en adelante, la Ley 11/2003); ${ }^{11}$ además, la Ley Orgánica 14/2003, del 20 de noviembre, de Reforma de la Ley Orgánica 4/2000, del 11 de enero, sobre derechos y libertades de los extranjeros en España y su integración social, modificada por la Ley Orgánica 8/2000, del 22 de diciembre; de la Ley 7/1985, del 2 de abril, reguladora de las Bases del Régimen Local; de la Ley 30/1992, del 26 de noviembre, de Régimen Jurídico de las Administraciones Públicas y del Procedimiento Administrativo Común y de la Ley 3/1991, del 10 de enero, de Competencia Desleal (en lo sucesivo, la LO 14/2003), ${ }^{12}$ y, finalmente, la Ley 27/2003, del 31 de julio, reguladora de la Orden de protección de las víctimas de la violencia doméstica (en adelante, la Ley 27/2003). ${ }^{13}$

4. Con la Ley $11 / 2003$, los delitos relacionados con la violencia doméstica fueron objeto de reforma: en primer lugar, las conductas que eran consideradas en el Código Penal como falta de lesiones, cuando se

dable fenómeno sobre los extranjeros/as que se encuentran en España, pues, en particular, ni la Ley de Extranjería (Ley Orgánica 4/2000, del 11 de enero, sobre derechos y libertades de los extranjeros en España, reformada por: a) Ley Orgánica 8/2000, del 22 de febrero, de Reforma de la Ley Orgánica 4/2000, del 11 de enero, sobre Derechos y Libertades de los extranjeros en España y su integración social; b) Ley Orgánica 11/2003, del 29 de septiembre, de medidas concretas en materia de seguridad ciudadana, violencia doméstica e integración social de los extranjeros, y c) Ley Orgánica 14/2003, del 20 de noviembre, de Reforma de la Ley Orgánica 4/2000, del 11 de enero, sobre derechos y libertades de los extranjeros en España y su integración social, modificada por la Ley Orgánica 8/2000, del 22 de diciembre; de la Ley 7/1985, del 2 de abril, Reguladora de las Bases del Régimen Local; de la Ley 30/1992, del 26 de noviembre, de Régimen Jurídico de las Administraciones Públicas y del Procedimiento Administrativo Común, y de la Ley 3/1991, del 10 de enero, de Competencia Desleal) ni su Reglamento (Real Decreto 864/2001, del 20 de julio, por el que se aprueba el Reglamento de Ejecución de la Ley Orgánica 4/2000, del 11 de enero, sobre derechos y libertades de los extranjeros en España y su integración social, reformada por Ley Orgánica 8/2000, del 22 de diciembre) se ocupaban del tema, sino que hemos tenido que esperar al Real Decreto 2393/2004, del 30 de diciembre, por el que se aprueba el Reglamento de la Ley Orgánica 4/2000, del 11 de enero, sobre derechos y libertades de los extranjeros en España y su integración social para contemplar este fenómeno desde el prisma de la extranjería.

11 BOE núm. 234, del 30 septiembre 2003.

12 BOE núm. 279, del 21 de noviembre de 2003.

13 BOE núm. 183, del 1o. de agosto de 2003. 
cometían en el ámbito doméstico, pasaron a considerarse delitos, con lo cual se abría la posibilidad de imponer pena de prisión y, en todo caso, la pena de privación del derecho a la tenencia y porte de armas. Por esta razón se ajustó técnicamente la falta regulada en el artículo 617; en segundo lugar, respecto a los delitos de violencia doméstica cometidos con habitualidad, se les dotó de una mejor sistemática, se amplió el círculo de sus posibles víctimas, se impuso, en todo caso, la privación del derecho a la tenencia y porte de armas, abriendo la posibilidad de que el juez o tribunal sentenciador acordara la privación de la patria potestad, tutela, curatela, guarda o acogimiento.

5. La aprobación de la LO 14/2003 se presentó como el último intento que el gobierno español realizaba, en un periodo muy breve de tiempo, para: a) por un lado, adecuar la legislación de extranjería a los términos y acuerdos internacionales aprobados en el seno de la Unión Europea, y b) por otro lado, hacer frente a la continua avalancha del "fenómeno migratorio", que, junto al considerable incremento del número de residentes extranjeros en territorio español, habían generado la necesidad de adaptar la legislación vigente a las decisiones comunitarias, $\mathrm{y}$, al mismo tiempo, incorporar determinadas consideraciones técnicas efectuadas en su día, por el Tribunal Supremo al anular varios artículos de la Ley de Extranjería. ${ }^{14}$ Los objetivos que se perseguían con esta reforma fueron los siguientes: 1o.) la mejora de la gestión, a través de la simplificación de los trámites administrativos, de la determinación de los tipos de visados y sus efectos; 2o.) la lucha contra el uso fraudulento de los procedimientos administrativos de gestión en esta materia, con la finalidad de favorecer la inmigración legal y la integración de los extranjeros en España, y 3o.) el refuerzo y mejora de los medios e instrumentos sancionadores para luchar contra la inmigración ilegal y el tráfico de seres humanos, potenciando para esto, la colaboración con las compañías de transporte aéreo internacional, con el fin de contar con la información sobre las personas que sean trasladadas al territorio español. ${ }^{15}$

14 En un sentido amplio, Heredia Sánchez, Lerdys y Ortega Giménez, Alfonso, “¿Qué cambios ha introducido el Tribunal Supremo en el Reglamento de ejecución de la Ley de Extranjería?", Iuris. Actualidad y Práctica del Derecho, Madrid, julio-agosto de 2003, núm. 74, La Ley, pp. 58-60.

15 En un sentido amplio, Ortega Giménez, Alfonso, "La última reforma de la Ley Extranjería española y la protección de datos de carácter personal”, Revista Chilena de 
6. La orden de protección a las víctimas de la violencia doméstica, consagrada en la Ley 27/2003, ha unificado los distintos instrumentos de amparo y tutela a las víctimas de estos delitos y faltas. Su objetivo es - como nos señala el propio legislador en su exposición de motivosque

a través de un rápido y sencillo procedimiento judicial, sustanciado ante el Juzgado de instrucción, pueda obtener la víctima un estatuto integral de protección que concentre de forma coordinada una acción cautelar de naturaleza civil y penal. Esto es, una misma resolución judicial que incorpore conjuntamente tanto las medidas restrictivas de la libertad de movimientos del agresor para impedir su nueva aproximación a la víctima, como las orientadas a proporcionar seguridad, estabilidad y protección jurídica a la persona agredida y a su familia, sin necesidad de esperar a la formalización del correspondiente proceso matrimonial civil.

Además, la principal innovación que presenta la Ley 27/2003 es el procedimiento diseñado, especialmente sencillo, y "accesible a todas las víctimas de la violencia doméstica, de modo que tanto éstas como sus representantes legales o las personas de su entorno familiar más inmediato puedan solicitarla sin formalismos técnicos o costes añadidos".

\section{LA VIOLENCIA DOMÉSTICA Y EL DERECHO DE EXTRANJERÍA ESPAÑOL}

7. Como bien señala la profesora Gaspar Blanch,

la residencia en España de mujeres extranjeras cada vez es mayor pero hasta hace poco había pasado desapercibido ese incremento numérico, debido entre otras causas, porque la gran mayoría están realizando trabajos de economía sumergida, trabajos en los que normalmente no se cotiza a la seguridad social, careciendo de contrato y de condiciones salariales, sin olvidar las que llegan a nuestro país en situación de irregularidad, muchas desconociendo el idioma. Una de las principales causas de llegada a España de la mujer inmigrante ha sido la reagrupación familiar, esta situación limita aún más su libertad, quedando condicionada su presencia en el país

Derecho Informático, Centro de Estudios en Derecho Informático de la Universidad de Chile, núm. 5, 2004, pp. 109-119. 
al permiso de su marido - ya que suele ser el hombre quien a la vez va a ser el sujeto de la reagrupación familiar, son la mujer y los hijos quienes se reagrupan en el país en torno a él-. ${ }^{16}$

No obstante, gracias a las últimas reformas operadas en materia de extranjería, como veremos a continuación, la situación de las mujeres extranjeras reagrupadas ha mejorado sensiblemente.

\section{La reforma de la Ley de Extranjería: efectos de la reagrupación} familiar en circunstancias especiales

8. Como ya hemos comentado, la LO 14/2003 respondió a dos motivos bien diferenciados: a) por un lado, el cumplimiento de diferentes disposiciones comunitarias en materia de tasas por la expedición de visados, de ejecución de resoluciones de expulsión dictadas por otros Estados miembros de la UE, de reconocimiento mutuo de las decisiones en materia de expulsión de nacionales de terceros países, y de la ayuda a la entrada, a la circulación y a la estancia de irregulares, y b), por otro lado, la incorporación de las modificaciones que introdujo la STS del 23 de marzo de 2003 antes mencionada, relativa a determinados aspectos relacionados con el Reglamento de Ejecución de la Ley de Extranjería - en su día, el Real Decreto 864/2001, del 20 de julio - tales como la libre circulación, la reagrupación familiar, la exención de visado, o la concesión de permisos de trabajo.

9. En lo que a nosotros nos interesa, la LO 14/2003 trajo consigo algunas modificaciones en torno al derecho de reagrupación familiar - que guardan estrecha relación con la violencia doméstica-, y que consistieron tanto en la modificación del apartado 2 del artículo 17 como en la introducción de dos nuevos apartados en los artículos 18 y 19 - todos de la Ley Orgánica 4/2000, del 11 de enero, sobre Derechos y Libertades de los extranjeros en España y su integración social, reformada por la Ley Orgánica 8/2000, del 22 de diciembre, por la Ley Orgánica 11/2003, del 29 de septiembre, y por la Ley Orgánica 14/2003, del 20 de noviem-

16 Véase Gaspar Blanch, Rosario Ana, "Violencia doméstica y mujer inmigrante", Boletín Aranzadi Penal, Pamplona, núm. 1/2003, 2003. 
bre de 2003 (en adelante LO 4/2000)—, ${ }^{17}$ de esta forma: ${ }^{18}$ a) se incorporó un nuevo presupuesto para el ejercicio de la reagrupación familiar en cadena por parte de un residente que lo fuera en virtud de una previa reagrupación, consistente en la existencia de una autorización de residencia y trabajo independiente de la autorización del reagrupante; b) en el caso de los ascendientes reagrupados, también se enfilan estas modificaciones, convirtiendo, si es posible, en aún más complicado el ejercicio de este derecho para los extranjeros en España, ya que se estableció que cuando se tratara de ascendientes reagrupados, éstos sólo podrían ejercer a su vez el derecho de reagrupación familiar, tras haber obtenido la condición de residentes permanentes y acreditado solvencia económica; al mismo tiempo, y de forma excepcional, se reconoció el derecho al ascendiente reagrupado, que tuviera a su cargo un hijo menor de edad o incapacitado, para ejercer el derecho de reagrupación en los términos previstos en el nuevo apartado 2 modificado, aunque dejando finalmente a las normas de desarrollo las condiciones para el ejercicio de este derecho; ${ }^{19}$ c) se modificó el artículo 19 de la LO 4/2000, referido a los efectos de la reagrupación familiar. En este caso, la modificación — que tenía un alcance de carácter positivo- se propuso hacer frente a los casos de violencia doméstica protegiendo al cónyuge maltratado, y, por tanto, se incluyó, en el apartado 1 del citado artículo, esta circunstancia como causa para obtener la autorización de residencia independiente, desde el momento en que se hubiera dictado una orden de protección a favor de la víctima del maltrato; d) se eliminó el requisito de convivencia con el cónyuge durante dos años en España, $\mathrm{y}$, en consecuencia, la previsión de reducción de dicho plazo por circunstancias de carácter familiar; e) se mantuvieron, para los hijos reagrupados, las dos circunstancias que dan

$17 B O E$ núm. 10, del 12 de enero de 2000; corrección de errores en $B O E$ núm. 20, del 24 de enero; $B O E$ núm. 307, del 23 de diciembre de 2000; corrección de errores en $B O E$ núm. 47, del 23 de febrero de 2001; BOE núm. 234, del 30 de septiembre de 2003; y, $B O E$ núm. 279, del 21 de noviembre de 2003.

18 Véase Heredia Sánchez, Lerdys y Ortega Giménez, Alfonso, "Últimas reformas en materia de extranjería", Iuris. Actualidad y Práctica del Derecho, Madrid, núm. 79, enero de 2004, pp. 28-36.

19 En consecuencia, quedó igualmente modificado el apartado 2 del artículo 18, pues conectaba lo dispuesto en el nuevo artículo 17.3 con el derecho de reagrupación de los extranjeros con sus familiares en España, en los mismos plazos que aparecen en la Ley de Extranjería, esto es, un año. 
lugar a la obtención de una autorización de residencia independiente: la mayoría de edad o la obtención de una autorización para trabajar, y f) se extendieron - en el nuevo apartado 3 del artículo 17- los efectos de la reagrupación a los ascendientes reagrupados para obtener una autorización de residencia independiente cuando obtuvieran una autorización para trabajar.

10. No discrimina la LO 14/2003 entre hombre y mujer, sino que, tras la citada reforma, la LO 4/2000, en su artículo 19.1, en materia de reagrupación familiar, establece que en el caso de que el cónyuge (reagrupado) - que podrá obtener una autorización de residencia independiente cuando obtenga una autorización para trabajar - "fuera víctima de violencia doméstica, podrá obtener la autorización de residencia independiente desde el momento en que se hubiera dictado una orden de protección a favor de la misma".

En consonancia con la Ley 27/2003, cuando el juzgado de instrucción dicte una orden de protección para la víctima de violencia doméstica - en este caso, el cónyuge extranjero-, en los casos en que existan indicios fundados de la comisión de un delito o falta contra la vida, integridad física o moral, libertad sexual, libertad o seguridad, se podrá obtener la pertinente autorización de residencia independiente.

11. Es evidente que la violencia doméstica es una cuestión seria, una lacra social, que en muchas ocasiones tiene un resultado nefasto - la muerte - de la víctima, pero, haciendo un mero examen jurídico, es evidente que la "generosidad" de este nuevo artículo 19.1 de la LO 4/2000 la convierte en una "vía para el fraude", y en "nueva forma de regularización" del inmigrante; y buena prueba de ello son las cifras arrojadas por el Instituto de la Mujer - ya comentadas-, en las que, con la LO 14/2003 el número de denuncias por malos tratos presentadas por extranjeros/as pasó, en el periodo 2003-2005, de 10,493 a 17,900, en el caso de las mujeres, y de 984 a 1,436, en el caso de los hombres. ${ }^{20}$ Quizá el "agujero" de la reforma está, en nuestra opinión, en la vinculación de la concesión de una autorización de residencia independiente de la del reagrupante (definitiva y no temporal) con la "simple existencia" de una orden de protección a favor de la misma, vulnerando, de esta forma, el derecho a la presunción de inocencia del presunto(a) agresor(a), cuando se debe-

20 Aunque es cierto que el incremento del número de denuncias puede ser por otras razones: consecuencia, por ejemplo, de una mayor toma de conciencia sobre el tema. 
ría esperar a la sentencia firme condenatoria para, en el caso del cónyuge extranjero maltratador(a), expulsarlo del territorio español - en virtud del artículo 57 de la LO 4/2000 —, 21 estableciendo una prohibición de entrada en el mismo por un periodo mínimo de tres años y máximo de diez — según lo previsto en el artículo 58 de la LO 4/2000—,22 y conceder, ahora sí, una autorización de residencia (definitiva) a la víctima.

\section{El nuevo Reglamento de Extranjería: residencia temporal en supuestos excepcionales}

12. El Consejo de Ministros, a propuesta del ministro de Trabajo y Asuntos Sociales, el 30 de diciembre de 2004, dio luz verde al Real decreto que aprueba el Reglamento de la Ley Orgánica, 4/2000, del 11 de enero, sobre derechos y libertades de los extranjeros en España y su integración social - Real decreto 2393/2004, del 30 de diciembre, por el que se aprueba el Reglamento de la Ley Orgánica 4/2000, del 11 de enero, sobre derechos y libertades de los extranjeros en España y su integración social (en lo sucesivo, RE) -.$^{23}$

13. Una de las novedades más interesantes del nuevo Reglamento de Extranjería ha sido - en lo que a nosotros aquí nos interesa- la incorporación al articulado del RE, de conformidad con lo dispuesto en el artículo 19.1 de la LO 4/2000, como una de las causas que permiten la obtención, por el cónyuge reagrupado, de una autorización de residencia temporal independiente, de la circunstancia consistente en que fuera víctima de violencia doméstica o de género, una vez dictada a su favor una orden judicial de protección. En este sentido, señala el artículo 41.2 del RE que "el cónyuge reagrupado podrá obtener una autorización de residencia temporal independiente cuando fuera víctima de violencia de género - manifestación de la violencia doméstica-, una vez dictada a favor de la misma una orden judicial de protección". De esta forma, el legislador — en consonancia con el tratamiento que le da a la violencia

21 En sentido contrario, por ejemplo, la sentencia de la Audiencia Provincial de Girona núm. 244/2004 (sección 3a.), del 24 de marzo, JUR 2004\158438.

22 En el mismo sentido, por ejemplo, el auto de la Audiencia Provincial de Huelva núm. 123/2004 (sección 3a.), del 24 de noviembre, JUR 2005\51096.

$23 B O E$ núm. 6, del 7 de enero de 2005; corrección de errores en $B O E$ núm. 130, del 10. de junio de 2005 . 
de género, ${ }^{24}$ en la Ley $1 / 2004$, del 28 de diciembre, de Medidas de Protección Integral contra la Violencia de Género- ${ }^{25}$ acota los supuestos de "regularización" circunscribiéndolos sólo a la mujer extranjera víctima de la violencia doméstica, discriminando al hombre extranjero víctima de malos tratos, y haciendo buena esa falacia de que "el hombre es el agresor y la mujer es la víctima". ${ }^{26}$

14. Pero no termina ahí la cosa, pues, en otro orden de cosas, entre los supuestos de concesión de autorizaciones de residencia temporal por circunstancias excepcionales previstos en el nuevo texto se establece en su artículo 45.4.a) que se podrá conceder una autorización por razones humanitarias "a los extranjeros víctimas de delitos por conductas violentas ejercidas en el entorno familiar", en los términos previstos por la Ley 27/2003, siempre que haya recaído sentencia por tales delitos.

Es mucho más coherente este precepto al vincular la concesión de una autorización de residencia temporal por circunstancias excepcionales con la existencia de una sentencia, dictada por el juez o tribunal que corresponda, y no con una simple orden de protección, dictada por el juzgado de instrucción de turno. Además, no se genera discriminación alguna entre hombre y mujer, pues las posibilidades de concesión de la autorización de residencia temporal por circunstancias excepcionales son iguales tanto para el extranjero como para la extranjera, víctimas de delitos por conductas violentas ejercidas en el entorno familiar.

\section{La dificil "armonización" de las normas de extranjería} españolas y la protección de la violencia de género

15. Las 18,745 denuncias por violencia doméstica presentadas por mujeres extranjeras durante 2006 han demostrado la difícil "armonización" de las normas de extranjería españolas y la protección de la violencia de género, ya que las mujeres extranjeras, al presentar la pertinente denuncia, salían de la comisaría con dos documentos, uno para proteger-

24 Véase en sentido amplio, Castillejo Manzanares, Raquel, "Cuestiones que suscita la Ley Orgánica de Medidas de Protección Integral contra la Violencia Doméstica", La Ley, Madrid, 7 de julio de 2005, pp. 1-6, y Domínguez Martín, Almudena, "Violencia de género, terrorismo doméstico", Lex Nova, Madrid, núm. 40, abril-junio de 2005, pp. $18-21$.

25 BOE núm. 313, del 29 de diciembre de 2004.

26 Véase en idéntico sentido, Gaspar Blanch, Rosario Ana, op. cit., nota 16. 
la de su pareja — orden de protección-, y otra para expulsarla del país - para abrirle procedimiento de expulsión en aplicación de la LE-.

16. De esta forma, mediante el "Protocolo de actuación de las Fuerzas y Cuerpos de Seguridad y de Coordinación con los órganos judiciales para la protección de las víctimas de violencia doméstica y de género", ${ }^{27}$ aprobado el pasado 28 de junio de 2005, se intenta conjugar ambas situaciones - la concesión de una orden de protección y la apertura de un procedimiento de expulsión en aplicación de la Ley de Extranjería-, con el fin de suspender los procedimientos de expulsión de las mujeres extranjeras irregulares, que hayan denunciado malos tratos de su pareja, y a las que el juez de turno les otorgue una orden de protección.

Además, se ha instruido a la policía para que informe a las denunciantes de que, en el caso de recibir la tutela judicial, tienen el derecho a obtener una autorización de residencia temporal por motivos excepcionales. Si lo obtiene, la mujer no será objeto de expulsión, sino que se le impondrá una multa de menor cuantía por infracción de la Ley de Extranjería.

17. A partir de hora, será el propio juez el que informe a la mujer extranjera denunciante de su derecho a solicitar la autorización de residencia temporal tan pronto como le sea concedida la orden de protección. Si la orden de protección es denegada, el expediente de infracción de la Ley de Extranjería sigue su curso, hasta acabar en la expulsión o, en su caso, en multa; $y$, en caso de concesión de la orden de protección, la apertura del posible expediente de expulsión quedará en suspenso por espacio de un mes, plazo en el que la mujer extranjera protegida deberá tramitar su solicitud de residencia temporal.

La presentación de la solicitud de residencia temporal supondrá la inmediata suspensión del procedimiento de expulsión, y la concesión de la autorización de residencia supondrá que a la mujer protegida no se la podrá expulsar, y que como máximo se le impondrá una multa — cuya cuantía será la inferior de las señaladas como posibles por la ley para la infracción cometida-.

27 Aprobado mediante Resolución del 28 de junio de 2005, de la Secretaría de Estado de Seguridad, por la que se acuerda la publicación del "Protocolo de actuación de las Fuerzas y Cuerpos de Seguridad y de Coordinación con los órganos judiciales para la protección de las víctimas de violencia doméstica y de género", actualizado a los principios generales y disposiciones de la Ley Orgánica 1/2004, del 28 de diciembre, de Medidas de Protección Integral contra la Violencia de Género. 
18. El problema se podrá plantear en el caso de que no se conceda la autorización de residencia temporal, cuyas opciones que caben pasan por: a) que la mujer extranjera protegida sea expulsada — salvo que se aprecien otras circunstancias que aconsejen la propuesta de multa-; o, b) que, habiendo dictado el juez de turno la sentencia favorable a la mujer extranjera maltratada, se solicite una autorización de residencia temporal por circunstancias excepcionales, a tenor del mencionado artículo 45.4.a) del RE.

\section{CONCLUSIONES}

19. Llegados a este punto, las conclusiones que podemos extraer serían las siguientes:

Primera. La violencia doméstica supone una violación de los derechos humanos, que no favorece, en modo alguno, la integración de los extranjeros en nuestro país. ${ }^{28}$

Segunda. Han sido muchos los avances que, en los últimos tiempos, se han producido en el derecho español en materia de lucha contra la violencia doméstica; pero como complemento a tales medidas se hace necesaria la puesta en marcha de programas de acción para combatirla, con el fin de poder reconocer las graves repercusiones de tal violencia, tanto en lo inmediato como a largo plazo, para la salud, el desarrollo psicológico y social y la igualdad de oportunidades de los afectados, ya sean éstos individuos, familias o comunidades, así como el alto coste social y económico que supone para toda la sociedad. ${ }^{29}$

28 Véase en el mismo sentido, Montalbán Huertas, Inmaculada, "Cuestiones y propuestas más relevantes suscitadas en el Primer Encuentro de Violencia Doméstica", Congreso "Violencia Doméstica", Madrid, Consejo General del Poder Judicial, Centro de Documentación Judicial, 2004, p. 359.

29 En este sentido, debemos destacar los programas puestos en marcha, desde el año 2000, en el marco de la Unión Europea, gracias a los Programas Daphne -Decisión 293/2000/CE, del Parlamento Europeo y del Consejo, del 24 de enero de 2000, por la que se aprueba un programa de acción comunitario (programa Daphne) (2000-2003) sobre medidas preventivas destinadas a combatir la violencia ejercida sobre los niños, los adolescentes y las mujeres (DOCE L 34, del 9 de febrero de 2000) - ; y Daphne II -Decisión 803/2004/CE del Parlamento Europeo, del 21 de abril de 2004, por la que se aprueba un programa de acción comunitario (2004-2008) para prevenir y combatir la violencia ejer- 
Tercera. No obstante, las medidas legales dictadas para contravenir la violencia doméstica quedarán en "papel mojado" si no se incrementan los servicios sociales de asistencia a la víctima, y se refuerzan los mecanismos de protección tras la interposición de la pertinente denuncia por parte de ésta.

Cuarta. La persona extranjera en su condición de no nacional se encuentra en una situación de exclusión social, al carecer, habitualmente, de los medios económicos y de recursos tan básicos como la información para defender sus derechos como víctima de delitos por conductas violentas ejercidas en el entorno familiar; ${ }^{30}$ ahora bien, la mujer extranjera - en perjuicio del hombre extranjero-, en nuestra opinión, en ningún caso merece un tratamiento preferente por parte del derecho de extranjería español.

Quinta. Además, no nos podemos olvidar de los extranjeros irregulares, que al no contar con el asesoramiento de abogado de oficio ni de justicia gratuita, es muy difícil presentar la denuncia pertinente en esta materia. ${ }^{31}$ De esta forma, en el marco del tratamiento judicial de la violencia doméstica se deben respetar los derechos a la asistencia jurídica gratuita y a la asistencia de intérprete - previstos en el artículo 22 de la LO $4 / 2000$ - , a todas las personas extranjeras, independientemente de su situación — legal o ilegal— en España.

\section{BIBLIOGRAFÍA}

CANTÓN ROMÁN, B., "La importancia del factor género en la violencia contra la mujer: un enfoque psicológico y social", Toga, Sevilla, núm. 143, julio-agosto de 2003.

CAstillejo MANZANARES, Raquel, "Cuestiones que suscita la Ley Orgánica de Medidas de Protección Integral contra la Violencia Doméstica", La Ley, Madrid, 7 de julio de 2005.

DOMÍNGUEZ MARTíN, Almudena, "Violencia de género, terrorismo doméstico", Revista Lex Nova, núm. 40, abril-junio de 2005.

cida sobre los niños, los jóvenes y las mujeres y proteger a las víctimas y grupos de riesgo (programa Daphne II) (DOCE L 143, del 30 de abril de 2004).

30 Véase Gaspar Blanch, Rosario Ana, op. cit., nota 16.

31 Idem. 
Esplugues Mota, C. y Lorenzo Segrelles, M. de, Legislación de extranjería, Valencia, Tirant lo Blanch, 2004.

GASPAR BLANCH, Rosario Ana, "Violencia doméstica y mujer inmigrante", Boletín Aranzadi Penal, Pamplona, Aranzadi, núm. 1/2003, 2003.

HEREDia SÁNCHEZ, Lerdys y OrTega GimÉnEZ, Alfonso, "Últimas reformas en materia de extranjería", IURIS. Actualidad y Práctica del Derecho, Madrid, núm. 79, enero de 2004.

___ "¿Qué cambios ha introducido el Tribunal Supremo en el Reglamento de Ejecución de la Ley de Extranjería?", Iuris. Actualidad y Práctica del Derecho, Madrid, núm. 74, julio-agosto de 2003.

LAurenzo Copello, P., "La violencia de género en la ley integral: valoración político-criminal", Revista Electrónica de Ciencia Penal y Criminología, 2005.

LÓPEZ ÁlVAREZ, Antonio et al., "Reflexiones multidisciplinares acerca de la violencia de género y doméstica", La Ley, Madrid, 14 de marzo de 2006.

LÓPEZ-MuÑIZ GoÑI, Miguel, La nueva Ley de Extranjería. Guía práctica y jurisprudencia, 3a. ed., Madrid, Colex, 2005.

ORTEGA GiMÉNEZ, Alfonso, "Notas sobre el Reglamento de Extranjería: nuevo Reglamento de Extranjería. Estructura, elementos y proceso de normalización", Iuris. Actualidad y Práctica del Derecho, Madrid, núm. 92, marzo de 2005.

VARIOS AUtORES, Congreso "Violencia doméstica", Madrid, Consejo General del Poder Judicial, Centro de Documentación Judicial, 2004.

_- Encuentros "Violencia doméstica", Madrid, Consejo General del Poder Judicial, Centro de Documentación Judicial, 2004. 